\title{
Surveillance Rate and its Impact on Survival of Hepatocellular Carcinoma Patients in South Korea: A Cohort Study
}

\section{Sanghyuk Im, MD \\ Eun Sun Jang, MD, PhD \\ Ju Hyun Lee, MD \\ Chung Seop Lee, MD \\ Beom Hee Kim, MD \\ Jung Wha Chung, MD \\ Jin-Wook Kim, MD, PhD \\ Sook-Hyang Jeong, MD, PhD}

Department of Internal Medicine, Seoul National University Bundang Hospital, Seoul National University College of

Medicine, Seongnam, Korea

Correspondence: Sook-Hyang Jeong, MD, PhD Department of Internal Medicine,

Seoul National University Bundang Hospital, Seoul National University College of Medicine, 82 Gumi-ro, 173 Beon-gil, Bundang-gu,

Seongnam 13620, Korea

Tel: 82-31-787-7029

Fax: 82-31-787-4052

E-mail: jsh@snubh.org

Received July 31, 2018

Accepted February 7, 2019

Published Online February 12, 2019

*Sanghyuk Im and Eun Sun Jang contributed equally to this work.

\begin{abstract}
Purpose
Though regular surveillance of hepatocellular carcinoma (HCC) for high-risk patients is widely recommended, its rate and effectiveness are not clear. The aim of this study is to investigate the actual rate of $\mathrm{HCC}$ surveillance and its related factors and to clarify its impact on survival in a Korean $\mathrm{HCC}$ cohort.
\end{abstract}

\section{Materials and Methods}

From 2012 to 2015,319 newly diagnosed HCC patients were prospectively enrolled at a tertiary hospital. Patient interviews based on a structured questionnaire survey were conducted. Surveillance was defined as liver imaging test $\geq 2$ times with at least 3-month interval within 2 years prior to HCC diagnosis.

\section{Results}

Surveillance rate was 39.8\%. Of the HCC patients with high-risk factors, only 182 (57.1\%) had knowledge for the need for regular surveillance, and 141 (44.2\%) had the accurate information about the method (ultrasound-based study). Surveillance group showed a higher proportion of early HCC $(p<0.001)$ and a longer overall survival $(p<0.001)$ compared to non-surveillance group. The multivariable Cox regression analysis indicated Child-Pugh class A, history of anti-viral therapy, low serum $\alpha$-fetoprotein level, non-advanced Barcelona Clinic Liver Cancer stage as independent predictors of overall survival, while regular surveillance was not $(\mathrm{p}=0.436)$.

\section{Conclusion}

Less than half of the newly diagnosed Korean HCC patients were under surveillance and the accurate perception for the need of HCC surveillance was insufficient. Of those under surveillance, most patients were diagnosed with early stage HCC, which led to the improved survival. Comprehensive efforts to optimize the surveillance program for the target population are warranted.

\section{Introduction}

Hepatocellular carcinoma (HCC) is a leading cause of cancer-related mortality throughout the world, with the sixth highest cancer incidence and the fourth highest cancer mortality in 2015 [1]. Despite continuous advances in both diagnostic and therapeutic modalities for HCC, the prognosis for HCC patients is still poor because they are often diagnosed
Key words

Hepatocellular carcinoma, Survival, Surveillance, Liver cirrhosis, Screening 
veillance among high-risk patients, the actual surveillance rate in the real-life setting is very low in most countries [5].

Moreover, the only randomized trial (conducted in China) that demonstrated a survival gain from surveillance had several methodological problems [6]. Meanwhile, the few cohort study results that showed survival improvement were weakened or abolished after correction for lead-time bias [7]. The most recent study on the U.S. Veterans showed a significant survival gain from surveillance. However, regular surveillance was defined as having more than one imaging study during the 2 years prior to HCC diagnosis [8]. This did not align with published guidelines, which recommend ultrasonography (US) in 6-month interval in a high HCC risk group [3,4]. Therefore, the actual impact of HCC surveillance is not clear due to the considerable heterogeneity of surveillance interval and modalities found in reported studies.

In this study, we aimed to investigate the actual receipt rate of HCC surveillance and its related factors, and to clarify its impact on survival in newly diagnosed HCC patients in South Korea.

\section{Materials and Methods}

\section{Study populations}

A total of 424 newly diagnosed, consecutively admitted HCC patients at the medical ward of Seoul National University Bundang Hospital (SNUBH), a tertiary hospital, were prospectively recruited from March 2012 to December 2015 and followed until December 2016. During this study period, 74 of 424 eligible patients (17.5\%) refused to participate in face-to-face interview. Of 350 enrolled patients, 31 patients were excluded from this study, because they were not candidates for HCC surveillance based on Korean guidelines for the early HCC detection program. Candidates had to be (1) $\geq 40$ years old with positive hepatitis B surface antigen (HBsAg) or HCV-RNA and / or (2) present with cirrhosis, regardless of age and etiology [9]. The excluded 31 patients had cryptogenic HCC without cirrhosis $(n=16)$, alcoholic liver disease-associated HCC without cirrhosis $(\mathrm{n}=10)$, nonalcoholic fatty liver disease-associated HCC without cirrhosis $(n=3)$, and HBV-related HCC but younger than $40(n=2)$. Finally, 319 newly diagnosed, untreated HCC patients were analyzed in the present study.

Following the Korean Liver Cancer Study Group (KLCSG) and the National Cancer Center (NCC) guidelines [10], which are similar to those of European Association of the Study of the Liver/American Association for the Study of Liver Diseases, HCC diagnosis was based on histological examination or typical radiographic findings. The latter was defined as arterial enhancement and portal or delayed washout of hepatic nodules on two or more of the following imaging studies: dynamic contrast-enhanced computed tomography (CT), dynamic contrast-enhanced magnetic resonance imaging (MRI), or hepatocyte specific contrastenhanced MRI. All portal vein thrombosis (PVT) was confirmed as tumor thrombosis by a specialized radiologist and bland PVT was not included. Cirrhosis diagnosis was based on clinical signs of portal hypertension, laboratory features (thrombocytopenia, hypoalbuminemia, and prolonged prothrombin time [PT]), endoscopic and/or US findings suggesting the presence of portal hypertension, and presence of nodular liver margins at US [11].

Liver disease etiologies were classified as HBV, for patients positive for $\mathrm{HBsAg}$; $\mathrm{HCV}$, for patients positive for $\mathrm{HCV}$ RNA; alcohol, for patients whose daily ethanol intake exceeded $20 \mathrm{~g}$ for women and $60 \mathrm{~g}$ for men for more than 10 years in the absence of any other known causes of liver disease; or as others (cryptogenic, non-alcoholic fatty liver disease, autoimmune, or genetic liver disease).

\section{Questionnaire survey and data collection}

Data were collected from face-to-face patient interviews, based on a structured questionnaire survey on HCC surveillance status (S1 Table). All interviews were overseen by a physician of the division of Gastroenterology and Hepatology. Data included demographics, socioeconomic status including educational level, marital status, alcohol consumption, smoking habits, family history of liver disease, and past medical history. All patients were asked about their perception of HCC risk and the need for surveillance. For patients who had taken surveillance within the 2 years prior to HCC diagnosis, detailed information was obtained about methods, frequency, interval, and date of the surveillance tests. For those who had not taken surveillance within 2 years prior to HCC diagnosis, reason for not receiving regular surveillance was asked categorically: (1) a lack of knowledge, (2) timecommitment, (3) limited accessibility, (4) cost, and (5) others. For validation, data obtained from patients undergoing follow up at SNUBH prior to HCC diagnosis for chronic liver disease $(n=63)$, were confirmed with patient's electronic medical records.

From medical records, laboratory results of $\mathrm{HBsAg}, \mathrm{HCV}$ RNA, and other routine tests including PT, platelet count, alanine/ aspartate transaminase, total bilirubin, albumin, creatinine, and $\alpha$-fetoprotein (AFP) were obtained. Tumor staging was assessed in accordance to the modified Union for International Cancer Control (mUICC) stage proposed by the Liver Cancer Study Group of Japan [12] and Barcelona Clinic Liver Cancer (BCLC) stage [13]. Those data were collected in 
a predesigned electronic data recording form.

\section{Definition of surveillance group for HCC}

Surveillance group ( $\mathrm{n}=127$ ) was defined as those who had received adequate liver imaging tests $\geq 2$ times with at least 3 -month interval within the 2 years prior to HCC diagnosis. This group was subdivided into a "surveillance interval within 6-month" group (more than two regular liver imaging tests within a 6-month interval before HCC diagnosis according to current guidelines $[3,4]$ ) and a "surveillance interval with 6-12 months" group (liver imaging test $\geq 2$ times but beyond a 6-month interval).

Non-surveillance group ( $\mathrm{n}=192)$ was defined as those who answered they had not undergone surveillance testing and had been diagnosed incidentally (first health check-up or during diagnostic procedures for other diseases) or symptomatically.

\section{Treatment, follow-up, and clinical outcome measure- ments}

All patients received appropriate anti-tumor therapy according to the attending physician's decision based on practice guidelines [10]. All patients were monitored for clinical status, laboratory tests, and liver imaging tests including US, CT, or MRI at 1 month after initial treatment and then were followed in 3- to 6-month interval, prospectively. For those who could not be treated with curative modality, follow-up interval was modified by medical status. Patient survival status and the cause of death were confirmed by final medical records or telephone calls to participants or family members.

\section{Statistical analysis}

Surveillance status and patient perceptions of HCC surveillance study were recorded descriptively. To compare demographic and tumor characteristics between the surveillance and the non-surveillance groups, and between the surveillance interval within 6 months and with 6- to 12-month groups, categorical variables were evaluated with a standard chi-square test, and continuous variables were analyzed by the independent-sample $t$ test.

Survival of each group was calculated based on the Kaplan-Meier method and compared by the log-rank test. Correction for lead-time bias, which represents improved survival due to earlier diagnosis, was performed based on a formula proposed by Duffy et al. [14], assuming an exponential distribution of the HCC sojourn time.

$$
E(s)=\frac{1-\mathrm{e}^{-\lambda t}}{\lambda}
$$

$E(s)$ is the lead time (days), $1 / \lambda$ is the mean sojourn time, and $t$ is the time of death after diagnosis of a screen-detected cancer. The expected additional follow-up duration due to lead-time was calculated and subtracted from the observed survival time. The HCC sojourn time was assumed to be 70 or 140 days, according to estimations reported in previous studies [15].

To elucidate independent predictors of overall survival in patients, Cox regression analysis was carried out with adjustment for factors that significantly affected overall survival in univariable analyses. All statistical evaluations were performed using SPSS software ver. 22 (IBM Corp., Armonk, $\mathrm{NY}$ ). p-value of $<0.05$ was considered statistically significant.

\section{Ethical statement}

The Institutional Review Board (IRB) of SNUBH approved this study, and informed written consents were obtained from all patients (IRB No. B-1201/143-002).

\section{Results}

\section{Surveillance rate for HCC and its related factors}

The study cohort was followed for $22.1 \pm 15.7$ months (mean \pm standard deviation [SD]) and 574.2 person-years (total). Among 319 newly diagnosed HCC patients, 127 (39.8\%) underwent HCC surveillance in the 2 years before the HCC diagnosis with a mean $\pm \mathrm{SD}$ interval of $7.8 \pm 4.3$ months. "Surveillance interval within 6 months" was performed in 70 patients $(21.9 \%)$ with a mean \pm SD interval of $5.1 \pm 1.3$ months. "Surveillance interval with 6-12 months" was performed in 57 patients $(17.9 \%)$ with a mean $\pm S D$ interval of $11.0 \pm 4.4$ months. Mean number of imaging tests received during the prior 2 years was $3.1 \pm 1.1(3.7 \pm 0.9$ and $2.3 \pm 0.8$ in within 6 months and with 6- to 12 -month interval groups, respectively). Serum AFP measurement was performed in 83 patients $(65.4 \%)$ combined with an imaging test.

Comparison of surveillance group and non-surveillance group was summarized in Table 1. The two groups were comparable for age, sex, serum bilirubin, creatinine, and PT (international normalized ratio). However, presence of cirrhosis ( $\mathrm{n}=106,83.5 \%$ vs. $\mathrm{n}=141,73.4 \%, \mathrm{p}=0.036)$ and history of anti-viral therapy ( $\mathrm{n}=89,70.1 \%$ vs. $\mathrm{n}=91,47.4 \%, \mathrm{p}<0.001$ ) were more frequent in the surveillance group than in the non-surveillance group. 
Table 1. Comparison of baseline and tumor characteristics according to HCC surveillance status

\begin{tabular}{|c|c|c|c|}
\hline Variable & $\begin{array}{l}\text { Surveillance } \\
(\mathrm{n}=127,39.8 \%)\end{array}$ & $\begin{array}{c}\text { Non-surveillance } \\
(n=192,60.2 \%)\end{array}$ & p-value ${ }^{a)}$ \\
\hline Age (yr) & $60.4 \pm 10.8$ & $60.8 \pm 11.4$ & 0.780 \\
\hline Male sex & $101(79.5)$ & $158(82.3)$ & 0.536 \\
\hline Follow-up duration (mo) & $26.5 \pm 15.5$ & $19.2 \pm 15.1$ & $<0.001$ \\
\hline \multicolumn{4}{|l|}{ ECOG } \\
\hline $0 / 1$ & $113(98.3)$ & $155(88.6)$ & 0.002 \\
\hline$\geq 2$ & $2(1.7)$ & $20(11.4)$ & \\
\hline \multicolumn{4}{|l|}{ Etiology } \\
\hline HBV & $99(78.0)$ & $133(69.3)$ & 0.047 \\
\hline $\mathrm{HCV}$ & $17(13.4)$ & $19(9.9)$ & \\
\hline $\mathrm{HBV}$ and $\mathrm{HCV}$ & 0 & $2(1.0)$ & \\
\hline Alcohol & $6(4.7)$ & $26(13.5)$ & \\
\hline Others & $5(3.9)$ & $12(6.3)$ & \\
\hline Cirrhosis & $106(83.5)$ & $141(73.4)$ & 0.036 \\
\hline \multicolumn{4}{|l|}{ Anti-viral therapy } \\
\hline HBV & $83(65.4)$ & $89(46.4)$ & $<0.001$ \\
\hline $\mathrm{HCV}$ & $6(4.7)$ & $2(1.0)$ & \\
\hline Platelet $\left(\times 10^{3} / \mathrm{mm}^{3}\right)$ & $111.0 \pm 54.7$ & $162.4 \pm 94.6$ & $<0.001$ \\
\hline ALT (IU/L) & $37.3 \pm 23.3$ & $59.6 \pm 54.8$ & $<0.001$ \\
\hline Albumin (g/dL) & $3.9 \pm 0.5$ & $3.8 \pm 0.5$ & 0.036 \\
\hline Bilirubin $(\mathrm{mg} / \mathrm{dL})$ & $1.1 \pm 1.5$ & $1.1 \pm 1.5$ & 0.695 \\
\hline PT INR & $1.2 \pm 0.2$ & $1.3 \pm 1.3$ & 0.381 \\
\hline Creatinine (mg/dL) & $0.9 \pm 0.4$ & $0.9 \pm 0.5$ & 0.817 \\
\hline \multicolumn{4}{|l|}{ Child-Pugh class } \\
\hline A & $112(88.2)$ & $153(79.7)$ & 0.047 \\
\hline $\mathrm{B} / \mathrm{C}$ & 15 (11.8) & $39(20.3)$ & \\
\hline \multicolumn{4}{|l|}{$\operatorname{AFP}(\mathrm{ng} / \mathrm{mL})$} \\
\hline$\leq 20$ & $77(60.6)$ & $74(38.7)$ & $<0.001$ \\
\hline $21-400$ & 40 (31.5) & $42(22.0)$ & \\
\hline$>400$ & $10(7.9)$ & $75(39.3)$ & \\
\hline \multicolumn{4}{|l|}{ Type of HCC } \\
\hline Nodular & $122(96.1)$ & $139(72.4)$ & $<0.001$ \\
\hline Infiltrative & $5(3.9)$ & $53(27.6)$ & \\
\hline Tumor size (cm) & $3.0 \pm 2.4$ & $7.0 \pm 5.0$ & $<0.001$ \\
\hline Portal vein thrombosis & $6(4.7)$ & $52(27.1)$ & $<0.001$ \\
\hline Extra-hepatic metastasis & $3(2.4)$ & $25(13.0)$ & 0.001 \\
\hline \multicolumn{4}{|l|}{ BCLC stage } \\
\hline $0 / \mathrm{A}$ & $102(80.3)$ & $81(42.2)$ & $<0.001$ \\
\hline $\mathrm{B}$ & $14(11.0)$ & $33(17.2)$ & \\
\hline $\mathrm{C}$ & $11(8.7)$ & $76(39.6)$ & \\
\hline $\mathrm{D}$ & 0 & $2(1.0)$ & \\
\hline \multicolumn{4}{|l|}{ mUICC stage } \\
\hline I & $80(63.0)$ & $54(28.1)$ & $<0.001$ \\
\hline II & $28(22.0)$ & $33(17.2)$ & \\
\hline III & $16(12.6)$ & $75(39.1)$ & \\
\hline IVA & 0 & $5(2.6)$ & \\
\hline IVB & $3(2.4)$ & $25(13.0)$ & \\
\hline
\end{tabular}

(Continued to the next page) 
Table 1. Continued

\begin{tabular}{|c|c|c|c|}
\hline Variable & $\begin{array}{l}\text { Surveillance } \\
(\mathrm{n}=127,39.8 \%)\end{array}$ & $\begin{array}{c}\text { Non-surveillance } \\
(n=192,60.2 \%)\end{array}$ & p-value ${ }^{a}$ \\
\hline \multicolumn{4}{|l|}{ Treatment modality } \\
\hline Surgical resection & $7(5.5)$ & $5(2.6)$ & $<0.001$ \\
\hline RFA & $28(22.0)$ & $7(3.6)$ & \\
\hline RFA+TACE & $21(16.5)$ & $14(7.3)$ & \\
\hline TACE & $69(54.3)$ & $147(76.6)$ & \\
\hline TACE+PEIT & $1(0.8)$ & 0 & \\
\hline Sorafenib & $1(0.8)$ & $3(1.6)$ & \\
\hline Supportive care & 0 & $16(8.3)$ & \\
\hline
\end{tabular}

Values are presented as mean \pm standard deviation or number (\%). ECOG, Eastern Cooperative Oncology Group; HBV, hepatitis B virus; $\mathrm{HCV}$, hepatitis $\mathrm{C}$ virus; ALT, alanine transferase; PT INR, prothrombin time international normalized ratio; AFP, $\alpha$-fetoprotein; HCC, hepatocellular carcinoma; BCLC, Barcelona Clinic Liver Cancer; mUICC, modified Union for International Cancer Control; RFA, radiofrequency ablation; TACE, transarterial chemoembolization; PEIT, percutaneous ethanol injection therapy. ${ }^{a)} \mathrm{p}$-value for comparisons between surveillance group and non-surveillance group.

Table 2. Perception for the hepatocellular carcinoma surveillance in Korean high-risk patients

\begin{tabular}{|c|c|c|c|}
\hline & $\begin{array}{c}\text { Total } \\
(n=319)\end{array}$ & $\begin{array}{l}\text { Surveillance group } \\
\qquad(\mathrm{n}=127,39.8 \%)\end{array}$ & $\begin{array}{c}\text { Non-surveillance group } \\
\qquad(\mathrm{n}=192,60.2 \%)\end{array}$ \\
\hline Knowledge of the need for surveillance & $182(57.1)$ & $106(83.5)$ & $76(39.6)$ \\
\hline \multicolumn{4}{|l|}{ Method of surveillance $\left.{ }^{a}\right)$} \\
\hline LFT & $163(51.1)$ & $97(76.4)$ & $66(34.4)$ \\
\hline AFP & $106(33.2)$ & $71(55.9)$ & $35(18.2)$ \\
\hline US & $141(44.2)$ & $91(71.7)$ & $50(26.0)$ \\
\hline $\mathrm{US}+\mathrm{AFP}$ & $99(31.0)$ & $67(52.8)$ & $32(16.7)$ \\
\hline $\mathrm{CT} / \mathrm{MRI}$ & $60(18.8)$ & $45(35.4)$ & $15(7.8)$ \\
\hline \multicolumn{4}{|l|}{ Source of information ${ }^{\text {b) }}$} \\
\hline Primary physician & $114(62.6)$ & $76(71.7)$ & $38(50.0)$ \\
\hline Family, friends, colleague & $16(8.8)$ & $9(8.5)$ & $7(9.2)$ \\
\hline TV/Radio/Newspaper & $43(23.6)$ & $18(17.0)$ & $25(32.9)$ \\
\hline Others & $9(4.9)$ & $3(2.8)$ & $6(7.9)$ \\
\hline
\end{tabular}

Values are presented as number (\%). LFT, liver function test; AFP, $\alpha$-fetoprotein; US, ultrasonography; CT, computed tomography; MRI, magnetic resonance image. ${ }^{\text {a)} M u l t i p l e ~ s e l e c t i o n, ~}{ }^{b}$ Percent was calculated among subjects who responded that they had knowledge of the need for regular surveillance.

\section{Perception for the surveillance for HCC in Korean high- risk patients}

Of 319 newly diagnosed HCC who were candidate for regular surveillance, 182 patients $(57.1 \%)$ had responded they had known about the need of surveillance (106 patients of surveillance group [83.5\%] and 76 patients of non-surveillance group [39.6\%]) (Table 2). Nonetheless, only 141 (44.2\% of total patients, $77.5 \%$ of subjects who had responded they had knowledge of the need for surveillance) had responded the US is needed for the HCC surveillance (Table 2). Subjects who had responded that simultaneous US and AFP needed were $99(31.0 \%)$ (Table 2).

Among the 182 patients who had responded they had known about the need of surveillance, 114 patients $(62.6 \%)$ obtained information about the need for HCC surveillance from their physician. Forty-three patients $(23.6 \%)$ responded that they got the information about the need for surveillance from the media, such as TV, radio, newspaper, or internet (Table 2).

In the non-surveillance group ( $\mathrm{n}=192)$, 'lack of knowledge' was the most common reason (95 patients, $49.5 \%$ ), following 
A

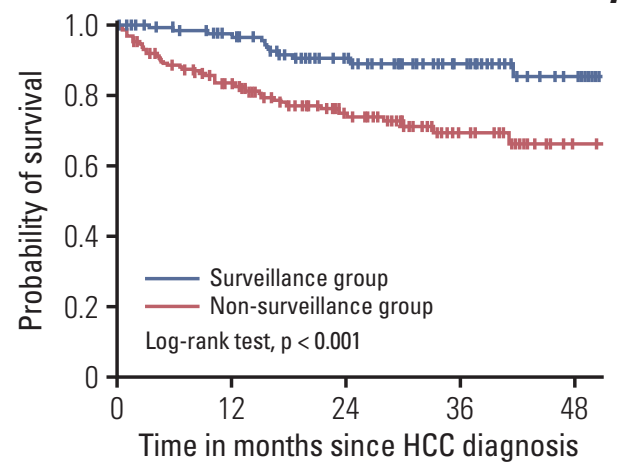

Surveillance

$\begin{array}{llllll}\text { Events } & 0 & 4 & 6 & 1 & 1\end{array}$

$\begin{array}{llllll}\text { No. at risk } & 127 & 103 & 65 & 37 & 17\end{array}$

Non-surveillance

$\begin{array}{llllll}\text { Events } & 0 & 28 & 11 & 3 & 1\end{array}$

$\begin{array}{llllll}\text { No. at risk } & 192 & 117 & 66 & 31 & 8\end{array}$

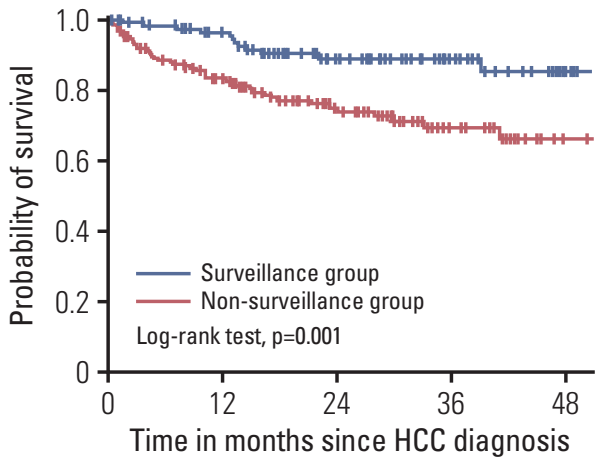

Surveillance

$\begin{array}{llllll}\text { Events } & 0 & 5 & 6 & 0 & 1\end{array}$

$\begin{array}{llllll}\text { No. at risk } & 127 & 96 & 59 & 31 & 10\end{array}$

Non-surveillance

$\begin{array}{llllll}\text { Events } & 0 & 28 & 11 & 3 & 1\end{array}$

C

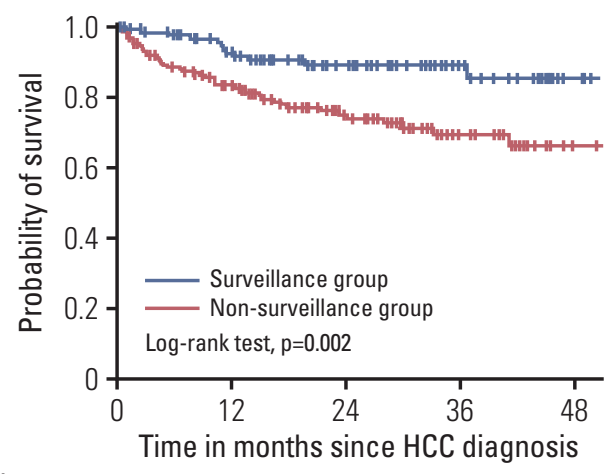

$\begin{array}{rrrrrr}\text { Surveillance } & & & & & \\ \text { Events } & 0 & 8 & 3 & 0 & 1 \\ \text { No. at risk } & 127 & 89 & 57 & 24 & 4 \\ \text { Non-surveillance } & & & & & \\ \text { Events } & 0 & 28 & 11 & 3 & 1 \\ \text { No. at risk } & 192 & 117 & 66 & 31 & 8\end{array}$

Fig. 1. Observed and corrected survivals of the surveillance group and the non-surveillance group. (A) Observed survival of the surveillance group was significantly better than that of the non-surveillance group. (B) Corrected survival of the surveillance group was significantly better than that of the non-surveillance group, even after adjustment with 70 days of hepatocellular carcinoma (HCC) sojourn time. (C) Corrected survival of the surveillance group was significantly better than that of the non-surveillance group, even after adjustment with 140 days of HCC sojourn time.

by 'time-commitment' $(\mathrm{n}=20,10.4 \%)$, 'unaffordable cost' $(\mathrm{n}=3,1.6 \%)$, 'limited accessibility to the hospital' $(\mathrm{n}=2,1.0 \%)$, and 'fear for bad result' ( $\mathrm{n}=1,0.5 \%)$. A total of 82 patients (42.7\% of non-surveillance group) were new to the health system and 97 patients (50.5\% of non-surveillance group) were newly diagnosed with liver cirrhosis. Of the patients with prior diagnosis of chronic liver disease $(n=131)$, lack of knowledge was also the most common reason for non-sur- veillance (55 patients, $42.0 \%$ ) indicating the need for increased awareness to HCC surveillance.

\section{Comparison of tumor characteristics according to HCC surveillance status}

As shown in Table 1, tumor diameter was smaller in the surveillance group compared to it in the non-surveillance 
A

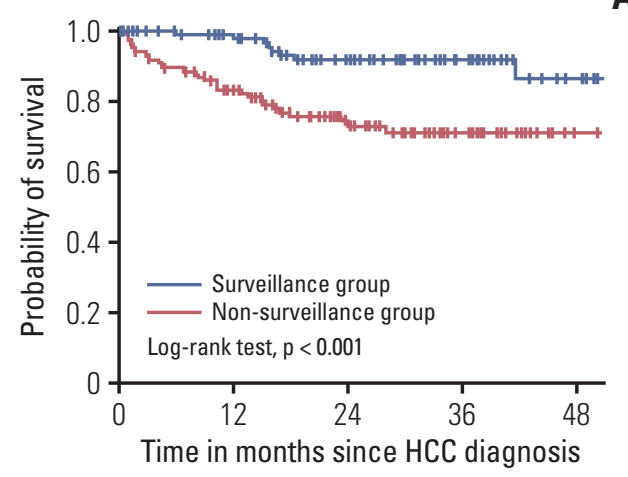

Surveillance

$\begin{array}{llllll}\text { Events } & 0 & 2 & 5 & 0 & 1\end{array}$

$\begin{array}{llllll}\text { No. at risk } & 106 & 87 & 55 & 31 & 13\end{array}$

Non-surveillance

$\begin{array}{llllll}\text { Events } & 0 & 21 & 9 & 1 & 0\end{array}$

$\begin{array}{llllll}\text { No. at risk } & 141 & 89 & 50 & 23 & 5\end{array}$

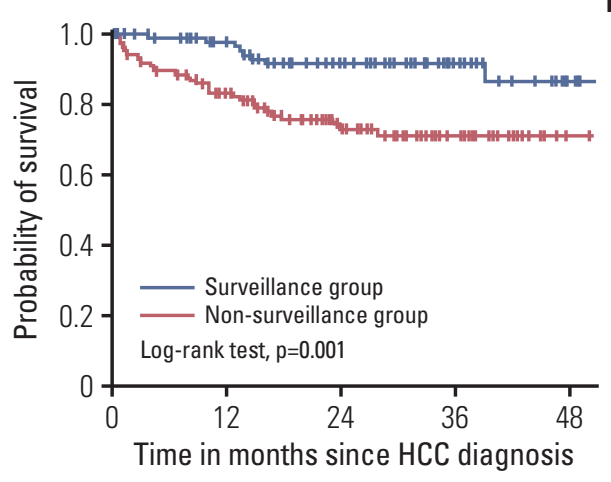

Surveillance

$\begin{array}{llllll}\text { Events } & 0 & 3 & 4 & 0 & 1\end{array}$

$\begin{array}{llllll}\text { No. at risk } & 106 & 81 & 51 & 25 & 7\end{array}$

Non-surveillance

$\begin{array}{llllll}\text { Events } & 0 & 21 & 9 & 1 & 0\end{array}$

C

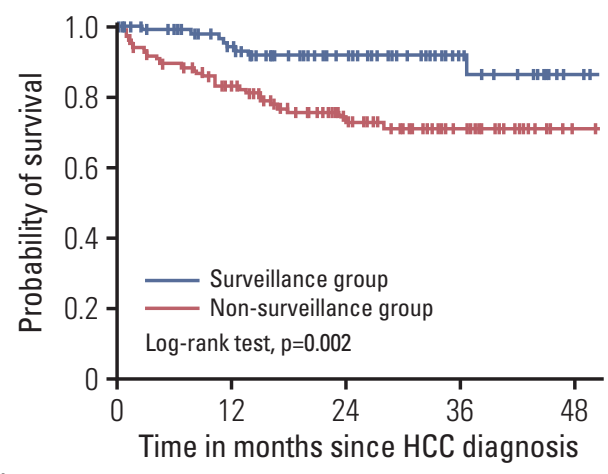

$\begin{array}{rrrrrr}\text { Surveillance } & & & & & \\ \text { Events } & 0 & 5 & 2 & 0 & 1 \\ \text { No. at risk } & 106 & 75 & 49 & 18 & 2 \\ \text { Non-surveillance } & & & & & \\ \text { Events } & 0 & 21 & 9 & 1 & 0 \\ \text { No. at risk } & 141 & 89 & 50 & 23 & 5\end{array}$

Fig. 2. Observed and corrected survivals of the surveillance group and the non-surveillance group in subgroup with liver cirrhosis. (A) Observed survival of the surveillance group was significantly better than that of the non-surveillance group in cirrhotic patients. (B) Corrected survival of the surveillance group was significantly better than that of the non-surveillance group with cirrhosis, even after adjustment with 70 days of hepatocellular carcinoma (HCC) sojourn time. (C) Corrected survival of the surveillance group was significantly better than that of the non-surveillance group with cirrhosis, even after adjustment with 140 days of HCC sojourn time.

group (3.0 $2.4 \mathrm{~cm}$ vs. $7.0 \pm 5.0 \mathrm{~cm}, \mathrm{p}<0.001)$. Frequency of serum $\mathrm{AFP} \leq 20 \mathrm{ng} / \mathrm{mL}$ at diagnosis (surveillance $60.6 \% \mathrm{vs}$. non-surveillance $38.7 \%, \mathrm{p}<0.001$ ) was higher and frequencies of PVT and extra-hepatic metastasis were significantly lower in the surveillance group than in the non-surveillance group (Table 1). As a result, patients with early HCC in BCLC stage 0 / $A$ were more frequent in the surveillance group than in the non-surveillance group ( $80.3 \%$ vs. $42.2 \%, \mathrm{p}<0.001)$. The curative treatment rate including surgical resection and RFA was higher in the surveillance group than in the nonsurveillance group (27.5\% vs. $6.2 \%, \mathrm{p}<0.001)$.

Comparisons of clinical characteristics between "surveillance interval within 6 months" group and "with 6-12 months" group were listed in S2 Table. There were no significant 
differences between the two groups for BCLC stage, mUICC stage, and treatment modality at the initial diagnosis.

\section{Impact of surveillance on the overall survival of HCC patients}

As shown in Fig. 1, mean overall survival was significantly better in the surveillance group than in the non-surveillance group (51.0 \pm 1.4 months vs. $41.2 \pm 1.7$ months, respectively, $\mathrm{p}<0.001$ ) (Fig. 1A). To correct lead-time bias, we calculated lead-time with an assumption of 2 different HCC sojourn times, 70 and 140 days. The significantly longer survival of the surveillance group was again observed with both 70 days ( $48.7 \pm 1.4$ months vs. $41.2 \pm 1.7$ months, $p=0.001$ ) (Fig. $1 B$ ) and 140 days ( $46.4 \pm 1.4$ months vs. $41.2 \pm 1.7$ months, $\mathrm{p}=0.002$ ) (Fig. 1C) assumptions.

We performed subgroup analysis for the impact of surveillance on the overall survival of HCC patients with cirrhosis. Among the cirrhotic patients (106 in the surveillance group, 141 in the non-surveillance group), mean overall survival was significantly better in the surveillance group than in the non-surveillance group ( $51.8 \pm 1.4$ months vs. $42.0 \pm 1.9$ months, $\mathrm{p}<0.001$, respectively) (Fig. 2A). With two different assumption of HCC sojourn times (70 and 140 days), the longer survivals of the surveillance group were still statistically significant (with 70 days assumption, $49.4 \pm 1.4$ months vs. $42.0 \pm 1.9$ months, $\mathrm{p}=0.001$, Fig. $2 \mathrm{~B}$; with 140 days assumption, $47.1 \pm 1.4$ months vs. $42.0 \pm 1.9$ months, $\mathrm{p}=0.002$, Fig. $2 \mathrm{C}$ ).

Nevertheless, overall survival in the "surveillance interval within 6 months" group and "with 6-12 months" group did not have a significant difference ( $50.2 \pm 2.0$ months vs. $51.8 \pm 2.0$ months, $\mathrm{p}=0.533$, respectively) (S3A Fig.). After correction for lead-time bias with 70 days and 140 days of HCC sojourn time, there were no significant differences in survival between the two groups with both 70 days (47.9 2.0 months vs. $49.4 \pm 2.0$ months, $\mathrm{p}=0.533$ ) (S3B Fig.) and 140 days ( $45.6 \pm$ 1.9 months vs. $47.1 \pm 2.0$ months, $\mathrm{p}=0.533$ ) (S3C Fig.) assumptions.

In the subgroup analysis of HCC patients with cirrhosis, overall survival in the "surveillance interval within 6 months" group (n=63) and "with 6-12 months" group $(\mathrm{n}=43)$ did not have a significant difference $(49.5 \pm 1.9$ months vs. $53.4 \pm 1.8$ months, $\mathrm{p}=0.434$, respectively) (S4A Fig.). After correction for lead-time bias with 70 days and 140 days of HCC sojourn time, there were no significant differences in survival between the two groups with both 70 days $(47.2 \pm 1.9$ months vs. $51.1 \pm 1.8$ months, $\mathrm{p}=0.434$ ) (S4B Fig.) and 140 days (44.9 \pm 1.9 months vs. $48.7 \pm 1.8$ months, $\mathrm{p}=0.434$ ) (S4C Fig.) assumptions.

According to multivariate analysis, Child-Pugh class A $(\mathrm{p}<0.001)$, history of anti-viral therapy $(\mathrm{p}=0.020)$, low serum AFP level ( $\mathrm{p}=0.003$ ), and BCLC stage non-C (stage $0 / \mathrm{A}, \mathrm{p}<$
0.001; stage $\mathrm{B}, \mathrm{p}=0.027$ ) were significant prognostic factors related to overall survival in Korean HCC patients. After adjusting those tumor related factors, regular surveillance was not an independent predictor of favorable survival of HCC patients (Table 3). In the subgroup analysis of HCC patients with cirrhosis, regular surveillance was not an independent predictor of favorable survival of HCC patients (Table 4).

\section{Discussion}

In the present study, we demonstrated that the previous surveillance rate was only $39.8 \%$ in Korean newly diagnosed HCC patients, and the adherence to the strict surveillance rate of 6-month interval according to the current guidelines $[3,4]$ was only $21.9 \%$, suggesting a suboptimal surveillance status. Although all patients were surveillance candidate for HCC, 182 patients $(57.1 \%)$ had known the need for regular surveillance, and among them, $77.5 \%$ knew the necessity of ultrasonography for HCC surveillance. About half (49.5\%) of the non-surveillance group answered they had never known about the need for surveillance, although $68.2 \%$ of them were aware of their liver disease. The adequate diagnosis of liver cirrhosis and the antiviral therapy were important factors to retain adherence to the regular surveillance in high risk group. Overall survival of the surveillance group was significantly better than that of the non-surveillance group, even with lead-time correction under various HCC sojourn time assumptions, but it was related with early diagnosis at curative stage according to multivariable analysis.

The surveillance rate in our study supported previous reports from the Korean Ministry of Health and Welfare in 2013 (44.2\%). A recent meta-analysis of 47 studies with 15,158 patients suggested only $41 \%$ of HCCs are detected by surveillance in the United States [16]. A recent retrospective cohort study from Sweden reported only $22 \%$ of HCCs were diagnosed by surveillance, and in more than one-third of cases, surveillance was indicated but missed [17].

Previous studies have categorized the causes of these disappointing surveillance rates into hospital/physician- and patient-related factors [18]. The former included insufficient physician understanding of HCC surveillance, which leads to insufficient recommendation of adequate surveillance for indicated patients. In the United States, a web-based survey of 131 primary care providers (PCP) in Dallas demonstrated only half believed that HCC surveillance reduced mortality. Furthermore, $45 \%$ of them believed in clinical examination, $59 \%$ in liver enzyme testing, and $89 \%$ in AFP alone as effective surveillance tests to detect HCC [19]. Another e-mail 
Table 3. Cox regression analysis to identify independent factors associated with survival

\begin{tabular}{|c|c|c|c|c|c|c|}
\hline \multirow{2}{*}{ Variable } & \multicolumn{3}{|c|}{ Univariate } & \multicolumn{3}{|c|}{ Multivariate } \\
\hline & HR & $95 \% \mathrm{CI}$ & p-value & HR & $95 \% \mathrm{CI}$ & p-value \\
\hline \multicolumn{7}{|l|}{ Age (yr) } \\
\hline$\geq 60$ & 1 & & & 1 & & \\
\hline$<60$ & 1.415 & $0.831-2.412$ & 0.201 & 1.268 & $0.668-2.406$ & 0.468 \\
\hline \multicolumn{7}{|l|}{ Sex } \\
\hline Male & 1 & & & 1 & & \\
\hline Female & 0.660 & $0.311-1.397$ & 0.277 & 0.986 & $0.434-2.239$ & 0.972 \\
\hline \multicolumn{7}{|l|}{ ECOG } \\
\hline$\geq 2$ & 1 & & & - & & \\
\hline $0 / 1$ & 0.268 & $0.119-0.600$ & 0.001 & - & - & - \\
\hline \multicolumn{7}{|l|}{ Etiology } \\
\hline Viral & 1 & & & - & & \\
\hline Non-viral & 1.008 & $0.476-2.137$ & 0.983 & - & - & - \\
\hline \multicolumn{7}{|l|}{ Cirrhosis } \\
\hline Yes & 1 & & & - & & \\
\hline No & 1.598 & $0.892-2.860$ & 0.115 & - & - & - \\
\hline \multicolumn{7}{|l|}{ Child-Pugh class } \\
\hline $\mathrm{B} / \mathrm{C}$ & 1 & & & 1 & & \\
\hline A & 0.308 & $0.174-0.547$ & $<0.001$ & 0.317 & $0.173-0.583$ & $<0.001$ \\
\hline \multicolumn{7}{|l|}{ Antiviral therapy } \\
\hline No & 1 & & & 1 & & \\
\hline Yes & 0.484 & $0.283-0.828$ & 0.008 & 0.467 & $0.246-0.887$ & 0.020 \\
\hline \multicolumn{7}{|l|}{ Tumor size (cm) } \\
\hline$\geq 5$ & 1 & & & - & & \\
\hline$<5$ & 0.161 & $0.089-0.293$ & $<0.001$ & - & - & - \\
\hline \multicolumn{7}{|l|}{ AFP level (ng/mL) } \\
\hline$>20$ & 1 & & & 1 & & \\
\hline$\leq 20$ & 0.262 & $0.138-0.498$ & $<0.001$ & 0.368 & $0.190-0.716$ & 0.003 \\
\hline \multicolumn{7}{|l|}{ BCLC stage } \\
\hline $\mathrm{C} / \mathrm{D}$ & 1 & & & 1 & & \\
\hline B & 0.315 & $0.157-0.633$ & 0.001 & 0.443 & $0.215-0.913$ & 0.027 \\
\hline $0 / \mathrm{A}$ & 0.085 & $0.044-0.165$ & $<0.001$ & 0.138 & $0.065-0.292$ & $<0.001$ \\
\hline \multicolumn{7}{|l|}{ Extra-hepatic metastasis } \\
\hline Yes & 1 & & & - & & \\
\hline No & 0.222 & $0.111-0.444$ & $<0.001$ & - & - & - \\
\hline \multicolumn{7}{|l|}{ Treatment modality } \\
\hline Others & 1 & & & - & & \\
\hline TACE+PEIT/TACE & 0.111 & $0.050-0.243$ & $<0.001$ & - & - & - \\
\hline Surgery/RFA/RFA+TACE & 0.010 & $0.002-0.051$ & $<0.001$ & - & - & - \\
\hline \multicolumn{7}{|l|}{ Surveillance } \\
\hline Non-surveillance & 1 & & & 1 & & \\
\hline Surveillance & 0.328 & $0.173-0.623$ & 0.001 & 0.755 & $0.372-1.532$ & 0.436 \\
\hline
\end{tabular}

HR, hazard ratio; CI, confidence interval; ECOG, Eastern Cooperative Oncology Group; AFP, $\alpha$-fetoprotein; BCLC, Barcelona Clinic Liver Cancer; TACE, transarterial chemoembolization; PEIT, percutaneous ethanol injection therapy; RFA, radiofrequency ablation. 
Table 4. Cox regression analysis to identify independent factors associated with survival of HCC patients with cirrhosis

\begin{tabular}{|c|c|c|c|c|c|c|}
\hline \multirow{2}{*}{ Variable } & \multicolumn{3}{|c|}{ Univariate } & \multicolumn{3}{|c|}{ Multivariate } \\
\hline & HR & $95 \% \mathrm{CI}$ & p-value & HR & $95 \% \mathrm{CI}$ & p-value \\
\hline \multicolumn{7}{|l|}{ Age (yr) } \\
\hline$\geq 60$ & 1 & & & 1 & & \\
\hline$<60$ & 1.060 & $0.566-1.987$ & 0.855 & 1.116 & $0.546-2.280$ & 0.764 \\
\hline \multicolumn{7}{|l|}{ Sex } \\
\hline Male & 1 & & & 1 & & \\
\hline Female & 0.666 & $0.279-1.591$ & 0.361 & 1.118 & $0.434-2.881$ & 0.817 \\
\hline \multicolumn{7}{|l|}{ ECOG } \\
\hline$\geq 2$ & 1 & & & - & & \\
\hline $0 / 1$ & 0.236 & $0.082-0.676$ & 0.007 & - & - & - \\
\hline \multicolumn{7}{|l|}{ Etiology } \\
\hline Viral & 1 & & & - & & \\
\hline Non-viral & 1.157 & $0.510-2.624$ & 0.728 & - & - & - \\
\hline \multicolumn{7}{|l|}{ Child-Pugh class } \\
\hline $\mathrm{B} / \mathrm{C}$ & 1 & & & 1 & & \\
\hline A & 0.255 & $0.131-0.498$ & $<0.001$ & 0.197 & $0.091-0.424$ & $<0.001$ \\
\hline \multicolumn{7}{|l|}{ Antiviral therapy } \\
\hline No & 1 & & & 1 & & \\
\hline Yes & 0.345 & $0.179-0.664$ & 0.001 & 0.488 & $0.230-1.037$ & 0.062 \\
\hline \multicolumn{7}{|l|}{ Tumor size $(\mathrm{cm})$} \\
\hline$\geq 5$ & 1 & & & - & & \\
\hline$<5$ & 0.182 & 0.093-0.355 & $<0.001$ & - & - & - \\
\hline \multicolumn{7}{|l|}{ AFP level (ng/mL) } \\
\hline$>20$ & 1 & & & 1 & & \\
\hline$\leq 20$ & 0.313 & $0.152-0.645$ & 0.002 & 0.347 & 0.159-0.754 & 0.008 \\
\hline \multicolumn{7}{|l|}{ BCLC stage } \\
\hline $\mathrm{C} / \mathrm{D}$ & 1 & & & 1 & & \\
\hline B & 0.468 & $0.216-1.015$ & 0.055 & 0.783 & $0.350-1.752$ & 0.551 \\
\hline $0 / \mathrm{A}$ & 0.097 & $0.044-0.210$ & $<0.001$ & 0.153 & $0.062-0.374$ & $<0.001$ \\
\hline \multicolumn{7}{|l|}{ Extra-hepatic metastasis } \\
\hline Yes & 1 & & & - & & \\
\hline No & 0.243 & $0.107-0.552$ & 0.001 & - & - & - \\
\hline \multicolumn{7}{|l|}{ Treatment modality } \\
\hline Others & 1 & & & - & & \\
\hline TACE+PEIT/TACE & 0.051 & $0.018-0.146$ & $<0.001$ & - & - & - \\
\hline Surgery/RFA/RFA+TACE & 0.003 & $0.000-0.028$ & $<0.001$ & - & - & - \\
\hline \multicolumn{7}{|l|}{ Surveillance } \\
\hline Non-surveillance & 1 & & & 1 & & \\
\hline Surveillance & 0.274 & $0.126-0.597$ & 0.001 & 0.704 & $0.296-1.674$ & 0.427 \\
\hline
\end{tabular}

HCC, hepatocellular carcinoma; HR, hazard ratio; CI, confidence interval; ECOG, Eastern Cooperative Oncology Group; AFP, $\alpha$-fetoprotein; BCLC, Barcelona Clinic Liver Cancer; TACE, trans-arterial chemoembolization; PEIT, percutaneous ethanol injection therapy; RFA, radiofrequency ablation.

based survey of 345 PCP in North Carolina demonstrated 189 PCP $(55 \%)$ did not recommend HCC surveillance. Of them $46(24 \%)$ PCP were unaware of any surveillance recommendations, 15 PCP $(8 \%)$ felt the benefit of surveillance was uncertain [20]. In the United Kingdom, 25\% of gastroenterol- ogists answered they were unaware of HCC surveillance guidelines [21]. From our data, $42.0 \%$ of the non-surveillance group with prior diagnosis of chronic liver disease including chronic hepatitis B or C and cirrhosis never knew about surveillance, and their physicians failed in educating them on 
regular surveillance tests. Thus, continuous education and reinforcement of guidelines among healthcare providers are required to increase surveillance rate.

Patient related factors included lack of knowledge of surveillance, time-commitment, accessibility to the hospital, and medical costs. A recent cohort study revealed that nearly half $(49.9 \%)$ of the patients reported barriers to receiving HCC surveillance, including difficulty with the scheduling process $(30.5 \%)$, costs of surveillance tests $(25.3 \%)$, and transportation difficulties (17.3\%) [22]. Another prospective cohort study reported that active alcohol consumption (hazard ratio [HR], 3.03 ; $95 \%$ confidence interval $[\mathrm{CI}], 2.03$ to 4.51 ) and a history of intravenous drug use (HR, 5.33; 95\% CI, 3.07 to 9.23) were the strongest predictors of suboptimal adherence to surveillance programs [23]. Our results also showed that alcoholic HCC patients tended to be in the non-surveillance group. Nonetheless, the major cause of the non-surveillance was insufficient education (49.5\% of patients in the non-surveillance group) rather than the physical factors: only $1.6 \%$ of patients reported that they had barriers to receiving HCC surveillance due to costs of surveillance test, $1.0 \%$ was due to limited accessibility to the hospital, and $10.4 \%$ was due to time-commitment. Of the patients with prior diagnosis of chronic liver disease, $42 \%$ answered that they did not know about the need of surveillance. In this regard, a recent single tertiary care center study in the United States revealed that patient involvement in their care (odd ratio, 3.4; 95\% CI, 1.5 to 7.9) was independent predictors of receiving surveillance [24]. Therefore, continued patient education and direct patient's involvement in decisions regarding HCC surveillance are warranted to improve the surveillance adherence.

Recently, survival benefits of HCC surveillance reported in many observational studies [25] have been challenged [7]. A recent systemic review reported that only one large randomized trial demonstrated the survival benefit of surveillance, but the study was limited by methodological flaws, and in 18 observational studies, lead- and length-time biases confounded the effects on mortality; therefore, it concluded that evidence supporting HCC screening impact on chronic liver disease patient mortality was weak [7]. A recent prospective cohort study from Spain showed that patients with suboptimal surveillance (defined as failure to complete two consecutive screening rounds) had more advanced HCC stages at diagnosis and shorter but non-significantly different median survivals than patients with optimal surveillance [23]. In contrast, a recent population-based cohort study from Taiwan reported that shorter US screening intervals were associated with better survival in HCC patents, even after adjusting for lead-time bias [26]. A retrospective cohort study from the United States also reported that a receipt of HCC surveillance was associated with $38 \%$ reduction in mortality risk [8]. A multi-center retrospective study from the Nether- lands also reported that survival rate was significantly higher in the surveillance group than in the non-surveillance group $(p<0.001)$ [27]. Similarly, our study further confirmed the survival benefit of surveillance after adjusting for lead-time bias.

Though a receipt of surveillance was not an independent factor for survival on multivariable analysis, diagnosis of HCC at early stage by way of surveillance was a significant independent prognostic factor. This result was similarly observed in European studies [28], in which surveillance interacts with prognosis through its effect on cancer stage.

The optimal interval for screening is recommended as 6 months in many guidelines [3,4], because several observational studies and recent large cohort studies have reported better outcomes in 6-month interval surveillance groups when compared with 12- to 24-month interval surveillance groups $[25,26]$. In contrast, a community based randomized study reported that there was no significant difference in the overall survival between 4- and 12-month US surveillance interval for patients with chronic viral hepatitis and thrombocytopenia [29]. A recent cost-effectiveness study proposed that the most optimal surveillance strategy is an initial screening age of 50 years old with a 1-year inter-screening interval [30]. Although it was shown as Supplementary data, our study also showed that the observed survival of HCC patients who undertook surveillance studies within 6-months interval and those with 6- to 12-month interval were not significantly different.

To the best of our knowledge, the present study is the first to reveal HCC surveillance utilization in high-risk patients in South Korea as a cohort study. However, our study had several limitations. First, we obtained surveillance utilization information from HCC patients using a structured questionnaire survey, rather than actual confirmation of test performance. Although we conducted a face-to-face interview with each patient, recall bias was inevitable. We compared the data obtained from the patients undergoing follow up at SNUBH $(n=63)$ prior to HCC diagnosis with the patient's electronic medical records for validation and confirm all correct surveillance status classification, however, we could not use their electronic medical records and we had no choice but to rely on the questionnaire survey for patients undergoing follow up at outside local clinic. To improve recalled response reliability, we designed the questionnaire to ask surveillance interval in three different ways: surveillance interval, the number of tests received within past 2 years, and the detailed surveillance date and method. We checked for inconsistent responses among the three questions during the data acquisition. For inconsistent responses, we compared their response with the medical record and tried to obtain the most accurate data. Despite of efforts to improve recalled response reliability, recall bias and possibility of misclassifi- 
cation between the two subgroups was inevitable, especially for the surveillance interval. This limitation undermined our study results that the observed survival of HCC patients who undertook surveillance studies within 6-months interval and those with 6- to 12-month interval were not significantly different. Therefore, well designed, prospective studies are needed to confirm the superiority of the semiannual over the annual surveillance. Second, this study did not include patients directly admitted to the surgical ward and thus mostly amenable to surgical resection. During our study period, 166 HCC patients were admitted to the surgical ward and received surgical resection. Nonetheless, surveillance group survival was better than that of the non-surveillance group, despite excluding many patients who underwent surgical resection with higher probability of surveillance. Thus, this selection bias may have caused underestimation of the survival benefit of HCC surveillance in this study, strengthening our survival benefit results. Third, lead-time bias may had affected the results of better survival of patients who had received surveillance imaging test. We took care to minimize the unavoidable lead-time bias by adjusting the survival of patients who had received surveillance imaging test. After this adjustment, the survival was still better in this group. Forth, the study population may not have truly reflected our national HCC patients because this study was conducted at a single tertiary center.

In conclusion, HCC surveillance can lead to significant overall survival benefit through early stage diagnosis in high-risk patients. However, less than half of the newly diagnosed Korean HCC patients were under surveillance and the accurate perception for the need of HCC surveillance was insufficient. Comprehensive efforts to optimize the surveillance program and the enlightenment for the need of regular surveillance for the target population should be warranted.

\section{Electronic Supplementary Material}

Supplementary materials are available at Cancer Research and Treatment website (https://www.e-crt.org).

\section{Conflicts of Interest}

Conflict of interest relevant to this article was not reported.

\section{Acknowledgments}

This study was supported by an intramural grant (No.02-2014024) from the Seoul National University Bundang Hospital.

\section{References}

1. Global Burden of Disease Cancer Collaboration, Fitzmaurice C, Allen C, Barber RM, Barregard L, Bhutta ZA, et al. Global, regional, and national cancer incidence, mortality, years of life lost, years lived with disability, and disability-adjusted lifeyears for 32 cancer groups, 1990 to 2015: a systematic analysis for the global burden of disease study. JAMA Oncol. 2017;3: 524-48.

2. Stuart KE, Anand AJ, Jenkins RL. Hepatocellular carcinoma in the United States: prognostic features, treatment outcome, and survival. Cancer. 1996;77:2217-22.

3. Bruix J, Sherman M; American Association for the Study of Liver Diseases. Management of hepatocellular carcinoma: an update. Hepatology. 2011;53:1020-2.

4. European Association for the Study of The Liver; European Organisation for Research and Treatment of Cancer. EASLEORTC clinical practice guidelines: management of hepatocellular carcinoma. J Hepatol. 2012;56:908-43.

5. Singal AG, Yopp A, Skinner CS, Packer M, Lee WM, Tiro JA. Utilization of hepatocellular carcinoma surveillance among American patients: a systematic review. J Gen Intern Med. 2012;27:861-7.

6. Zhang BH, Yang BH, Tang ZY. Randomized controlled trial of screening for hepatocellular carcinoma. J Cancer Res Clin Oncol. 2004;130:417-22.
7. Kansagara D, Papak J, Pasha AS, O'Neil M, Freeman M, Relevo R, et al. Screening for hepatocellular carcinoma in chronic liver disease: a systematic review. Ann Intern Med. 2014;161:261-9.

8. Mittal S, Kanwal F, Ying J, Chung R, Sada YH, Temple S, et al. Effectiveness of surveillance for hepatocellular carcinoma in clinical practice: a United States cohort. J Hepatol. 2016;65: 1148-54.

9. Kim DY, Kim HJ, Jeong SE, Kim SG, Kim HJ, Sinn DH, et al. The Korean guideline for hepatocellular carcinoma surveillance. J Korean Med Assoc. 2015;58:385-97.

10. Lee JM, Park JW, Choi BI. 2014 KLCSG-NCC Korea Practice Guidelines for the management of hepatocellular carcinoma: HCC diagnostic algorithm. Dig Dis. 2014;32:764-77.

11. Kudo M, Zheng RQ, Kim SR, Okabe Y, Osaki Y, Iijima H, et al. Diagnostic accuracy of imaging for liver cirrhosis compared to histologically proven liver cirrhosis: a multicenter collaborative study. Intervirology. 2008;51 Suppl 1:17-26.

12. Minagawa M, Ikai I, Matsuyama Y, Yamaoka Y, Makuuchi M. Staging of hepatocellular carcinoma: assessment of the Japanese TNM and AJCC/UICC TNM systems in a cohort of 13,772 patients in Japan. Ann Surg. 2007;245:909-22.

13. Forner A, Reig ME, de Lope CR, Bruix J. Current strategy for staging and treatment: the BCLC update and future prospects. 
Semin Liver Dis. 2010;30:61-74.

14. Duffy SW, Nagtegaal ID, Wallis M, Cafferty FH, Houssami N, Warwick J, et al. Correcting for lead time and length bias in estimating the effect of screen detection on cancer survival. Am J Epidemiol. 2008;168:98-104.

15. Cucchetti A, Trevisani F, Pecorelli A, Erroi V, Farinati F, Ciccarese $\mathrm{F}$, et al. Estimation of lead-time bias and its impact on the outcome of surveillance for the early diagnosis of hepatocellular carcinoma. J Hepatol. 2014;61:333-41.

16. Singal AG, Pillai A, Tiro J. Early detection, curative treatment, and survival rates for hepatocellular carcinoma surveillance in patients with cirrhosis: a meta-analysis. PLoS Med. 2014;11: e1001624.

17. Edenvik P, Davidsdottir L, Oksanen A, Isaksson B, Hultcrantz $\mathrm{R}$, Stal P. Application of hepatocellular carcinoma surveillance in a European setting: what can we learn from clinical practice? Liver Int. 2015;35:1862-71.

18. Selvapatt N, House H, Brown A. Hepatocellular carcinoma surveillance: are we utilizing it? J Clin Gastroenterol. 2016;50: e8-12.

19. Dalton-Fitzgerald E, Tiro J, Kandunoori P, Halm EA, Yopp A, Singal AG. Practice patterns and attitudes of primary care providers and barriers to surveillance of hepatocellular carcinoma in patients with cirrhosis. Clin Gastroenterol Hepatol. 2015;13:791-8.e1.

20. McGowan CE, Edwards TP, Luong MU, Hayashi PH. Suboptimal surveillance for and knowledge of hepatocellular carcinoma among primary care providers. Clin Gastroenterol Hepatol. 2015;13:799-804.

21. Thompson Coon J, Rogers G, Hewson P, Wright D, Anderson R, Cramp M, et al. Surveillance of cirrhosis for hepatocellular carcinoma: systematic review and economic analysis. Health Technol Assess. 2007;11:1-206.

22. Farvardin S, Patel J, Khambaty M, Yerokun OA, Mok H, Tiro JA, et al. Patient-reported barriers are associated with lower hepatocellular carcinoma surveillance rates in patients with cirrhosis. Hepatology. 2017;65:875-84.

23. Mancebo A, Gonzalez-Dieguez ML, Navascues CA, Cadahia V, Varela M, Perez R, et al. Adherence to a semiannual surveillance program for hepatocellular carcinoma in patients with liver cirrhosis. J Clin Gastroenterol. 2017;51:557-63.

24. Singal AG, Volk ML, Rakoski MO, Fu S, Su GL, McCurdy H, et al. Patient involvement in healthcare is associated with higher rates of surveillance for hepatocellular carcinoma. J Clin Gastroenterol. 2011;45:727-32.

25. Santi V, Trevisani F, Gramenzi A, Grignaschi A, Mirici-Cappa F, Del Poggio P, et al. Semiannual surveillance is superior to annual surveillance for the detection of early hepatocellular carcinoma and patient survival. J Hepatol. 2010;53:291-7.

26. Wu CY, Hsu YC, Ho HJ, Chen YJ, Lee TY, Lin JT. Association between ultrasonography screening and mortality in patients with hepatocellular carcinoma: a nationwide cohort study. Gut. 2016;65:693-701.

27. van Meer S, de Man RA, Coenraad MJ, Sprengers D, van Nieuwkerk KM, Klumpen HJ, et al. Surveillance for hepatocellular carcinoma is associated with increased survival: results from a large cohort in the Netherlands. J Hepatol. 2015;63:1156-63.

28. Trevisani F, De Notariis S, Rapaccini G, Farinati F, Benvegnu L, Zoli M, et al. Semiannual and annual surveillance of cirrhotic patients for hepatocellular carcinoma: effects on cancer stage and patient survival (Italian experience). Am J Gastroenterol. 2002;97:734-44.

29. Wang JH, Chang KC, Kee KM, Chen PF, Yen YH, Tseng PL, et al. Hepatocellular carcinoma surveillance at 4- vs. 12-month intervals for patients with chronic viral hepatitis: a randomized study in community. Am J Gastroenterol. 2013;108:41624.

30. Lee YH, Choi KS, Jun JK, Suh M, Lee HY, Kim YN, et al. Costeffectiveness of liver cancer screening in adults at high risk for liver cancer in the republic of Korea. Cancer Res Treat. 2014 46:223-33. 